\title{
Tuberculous Dactylitis: An Unusual Finding Demanding Invasive Diagnosis
}

\section{Gabriel Aisenberg*}

The University of Texas Health Science Center, USA

\begin{abstract}
Tuberculous dactylitis is an unusual form of bone tuberculosis characterized by non-specific clinical and imaging features. Tissue pathological and microbiological examination represent the hallmark of diagnosis. This is the case of a woman on tumour necrosis alpha blocker presenting with chronic osteomyelitis and arthritis of a finger caused by Mycobacterium tuberculosis.
\end{abstract}

Keywords: Mycobacterium tuberculosis; Tuberculous dactylitis; Proximal interphalangeal

\section{Introduction}

Tuberculous dactylitis, first described in 1886 [1], represents an uncommon form of bone tuberculous infection predominant in childhood. Tuberculosis of the hand usually starts as tenosynovitis, and eventually spreads to bones and joints [2]. Atraumatic digital fractures caused by this condition are previously described [3]. The recommended workup is focused on the assessment of a chronic joint inflammation, and includes a combination of images and tissue pathology and culture. This is the case of an adult on treatment with etanercept that presented with a protracted digital osteomyelitis caused by M.tuberculosis.

\section{Case Report}

A 72 year old Chinese woman from Baton Rouge, Louisiana, with history of hypertension and adult's Still's disease on etanercept and prednisone $15 \mathrm{mg} /$ day, complained of a 1 year history of swelling around the Proximal Interphalangeal (PIP) joint of the right middle finger. She was not aware of previous PPD or gamma-interferon based assay. She didn't recall having taken latent-tuberculous therapy. The swelling started a few days after a blunt trauma while gardening. The patient recalled some early blisters full with clear fluid. After 3 months of topical neomycin with progression of symptoms a dorsal incision over the PIP joint was performed; no cultures were sent. After a stable period, the swelling worsened progressively decreasing the range of motion. Six months later a granulomatous mass was excised in an outside hospital. The biopsy reported non-necrotic micro granulomas. Fungal and acid-fast stains were negative. The culture grew Pseudomonas aeruginosa sensitive to quinolones. Fourteen days of ciprofloxacin did not modify the picture. One month later, in 2005, presented to our hospital's Plastic Surgery clinic in Houston, Texas. The remainder of her review of systems was negative, but for intermittent papular $4 \mathrm{limb}$ rash. Temperature was $36.9^{\circ} \mathrm{C}$, pulse $68 / \mathrm{min}$, blood pressure was 118/68 $\mathrm{mmHg}$, weight $62 \mathrm{~kg}$. There was no thrush, no palpable lymph nodes, normal heart sounds with a $2 / 6$ systolic aortic murmur; clear lung breath sounds; no palpable liver or spleen over a non-tender abdomen; tiny macular rash on the anterior aspect of both forearms and knees. Exposure of the right PIP joint with destruction of its cartilaginous surface was noticed on hand examination. The extensor tendon was liquefied (Figure 1).

Laboratory showed WBC 6300/1 (76\% neutrophil, 21\% lymphocytes); haemoglobin 13.5g/dL; platelets $130,000 / 1$; glucose 121 $\mathrm{mg} / \mathrm{dL}$; creatinine $0.8 \mathrm{mg} / \mathrm{dL}$; normal liver function tests. A plain film of the affected hand done (Figure 2) on the clinic day showed erosion of proximal and distal aspects of the bone around the affected PIP.
Stitches from the previous surgery were also visible. Chest X-ray was normal. Two days after this visit the mycobacterial culture from the synovial biopsy done in the previous hospital was positive. Two days later DNA amplification identified the organism as Mycobacterium tuberculosis. Patient started treatment with rifampin $600 \mathrm{mg} /$ day, isoniazide $300 \mathrm{mg} /$ day, pyrazinamide $1000 \mathrm{mg} /$ day, ethambutol 800 $\mathrm{mg} /$ day, and pyridoxine, planned to receive 9 months of treatment. Her condition did not change 2 weeks later. After that visit she returned to Louisiana and got lost of follow up.

\section{Discussion}

Skeletal tuberculosis accounts for 1-5\% of extrapulmonary tuberculosis. It results from reactivation of latent foci seeded during the primary illness; or new hematogenous or lymphatic spread from newly reactivated tuberculosis. The compromise of the phalanxes, this is tuberculous dactylitis, is an unusual form, more common in children. The diagnosis is usually delayed due to the lack of specific signs or symptoms. Radiographic manifestations include soft tissue

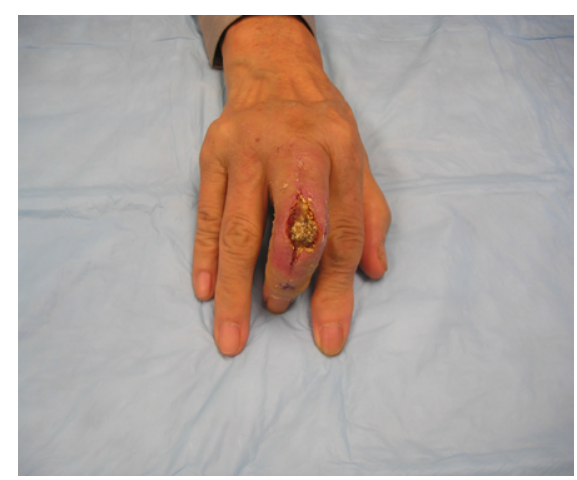

Figure 1: Exposure of the right PIP joint with destruction of its cartilaginous surface on hand examination. The extensor tendon appears liquefied.

*Corresponding author: Gabriel Aisenberg, Department of Internal Medicine The University of Texas Health Science Center in Houston 6431 Fannin street MSB 1.122, Houston, Texas 77030, USA, Tel: 713-500-6714; Fax: 713-500-6722; E-mail: gaisenberg@yahoo.com

Received April 24, 2014; Accepted July 18, 2014; Published July 21, 2014

Citation: Aisenberg G (2014) Tuberculous Dactylitis: An Unusual Finding Demanding Invasive Diagnosis. J Clin Case Rep 4: 389. doi:10.4172/21657920.1000389

Copyright: (c) 2014 Aisenberg G. This is an open-access article distributed under the terms of the Creative Commons Attribution License, which permits unrestricted use, distribution, and reproduction in any medium, provided the original author and source are credited. 


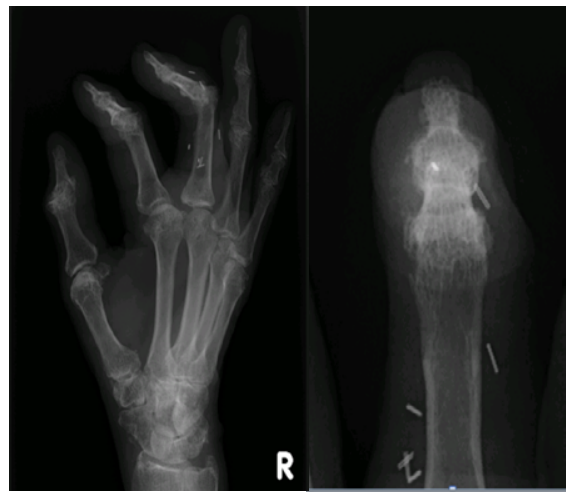

Figure 2: Plain film of the hand with amplification of the affected finger shows erosion of proximal and distal aspects of the bone around the affected PIP. Stitches from the previous surgery are also visible.

swelling (90\%), osteopenia (72\%), joint space narrowing (66\%), cysts (66\%), erosions $(64 \%)$, bony sclerosis $(20 \%)$, periostitis $(15 \%)$ or calcifications (5\%) [4]. Radionuclide scanning usually shows uptake of Technetium 99 diphosphonate, and T2-weighted images in magnetic resonance may show bone marrow expansion. Though abnormal, these findings lack enough diagnostic specificity $[5,6]$. Granulomata in synovial biopsy are present in about $80 \%$ of patients; synovial fluid culture is positive in $79 \%$ and synovial tissue culture in about $90 \%$. The Ziehl Neelsen stain is reported negative in most previous cases [7], when the biopsy is obtained using a fine needle. In our case, even the surgical biopsy was of low yield in that regard. Local trauma prior to the infection is reported in up to $40 \%$ of cases, but this may represent recall bias. The use of TNF alpha-blockers is reportedly associated with an increased relative risk of tuberculosis reactivation. This seems to be more common for infliximab than for etanercept, drug that this patient was using $[8,9]$.

\section{Conclusion}

Tuberculous dactylitis is an unusual form of bone tuberculosis. The clinical presentations and imaging studies are non-specific. Tissue pathological and microbiological examination represent the hallmark of diagnosis.

\section{References}

1. Pearlman HS, Warren RF (1961) Tuberculousdactylitis. See comment in PubMed Commons below Am J Surg 101: 769-771.

2. Al-Qattan MM, Bowen V, Manktelow RT. J of Hand Surg 1994; 19B: 234-237

3. Umansky AL, Schlesinger PT, Greenberg BB (1947) Tuberculousdactylitis in the adult. See comment in PubMed Commons below Arch Surg 54: 67-78.

4. Leung PC (1978) Tuberculosis of the hand. See comment in PubMed Commons below Hand 10: 285-291.

5. Yoon CJ, Chung HW, Hong SH, Kim CJ, Kang HS (2001) MR findings of tuberculousdactylitis: case report. See comment in PubMed Commons below Eur J Radiol 39: 163-167.

6. Kim MW, Lim ST, Sohn MH (2004) Tc-99m MDP three-phase bone scintigraphy of tuberculousdactylitis involving the middle finger in the adult. See comment in PubMed Commons below ClinNucl Med 29: 312-315.

7. Narayana Reddy RA, Narayana SM, Shariff S (2013) Role of fine-needle aspiration cytology and fluid cytology in extra-pulmonary tuberculosis. See comment in PubMed Commons below DiagnCytopathol 41: 392-398.

8. Horsburgh CR Jr (2004) Priorities for the treatment of latent tuberculosis infection in the United States. See comment in PubMed Commons below N Engl J Med 350: 2060-2067.

9. Wallis RS, Broder MS, Wong JY, Hanson ME, Beenhouwer DO (2004) Granulomatous infectious diseases associated with tumor necrosis factor antagonists. See comment in PubMed Commons below Clin Infect Dis 38: 1261-1265. 